\title{
Clinical and genetic features in autosomal recessive and X-linked Alport syndrome
}

\author{
${ }^{1}$ Yanyan Wang, ${ }^{1}$ Vanessa Sivakumar, ${ }^{1,2}$ Mardhiah Mohammad, ${ }^{1}$ Deb Colville, ${ }^{3}$ Helen \\ Storey, ${ }^{3}$ Frances Flinter, ${ }^{1}$ Hayat Dagher, ${ }^{1}$ Judy Savige \\ ${ }^{1}$ The University of Melbourne, Department of Medicine (Northern Health), \\ AUSTRALIA, ${ }^{2}$ International Islamic University of Malaysia, Kuala Lumpur, Malaysia, \\ and ${ }^{3}$ Department of Genetics, Guy's and St Thomas' Hospital Trust, London, UK
}

Address for Correspondence:

Prof Judy Savige

The University of Melbourne (Northern Health

The Northern Hospital

Epping VIC 3076

AUSTRALIA

Tel: + 61384058823

FAX: + 61384058724

Email: jasavige@unimelb.edu.au 


\section{Abstract}

Background: This study determined the family history and clinical features that suggested autosomal recessive rather than X-linked Alport syndrome.

Methods: All patients had the diagnosis of Alport syndrome and the mode of inheritance confirmed by genetic testing, and underwent examination at a single centre.

Results: Patients comprised 9 males and 6 females with autosomal recessive Alport syndrome, and 18 males and 22 females with X-linked disease.

Fourteen (93\%) individuals with autosomal recessive Alport syndrome developed early end-stage renal failure, all 15 had hearing loss, and most had lenticonus (12, $80 \%)$, and a central $(13,87 \%)$ or peripheral $(13,87 \%)$ retinopathy. These features occurred as often as in males with X-linked disease.

Females with autosomal recessive inheritance were less likely to have an affected family member in another generation ( $\mathrm{p}=0.01)$ than females with $\mathrm{X}$-linked disease. They were more likely to have renal failure $(p=0.003)$, hearing loss $(p=0.02)$ and lenticonus $(p<0.001)$. Fifty $\%$ had a central retinopathy compared with $18 \%$ with $X$ linked disease $(p=0.14)$, but peripheral retinopathy prevalence was not different $(p=0.64)$. Nonsense mutations accounted for $67 \%(8 / 12)$ of these disease-causing mutations.

Conclusions: Autosomal recessive inheritance is increased in females with Alport syndrome and early onset renal failure, hearing loss, lenticonus, and, possibly, central retinopathy.

Key words: Alport syndrome, retinopathy, nonsense mutations 


\section{Introduction}

Alport syndrome is characterised by hematuria, progressive renal failure, hearing loss, lenticonus, perimacular flecks and a peripheral coalescing retinopathy.[1, 2] Xlinked inheritance accounts for $85 \%$ patients [3] and is caused by mutations in the COL4A5 gene.[4] Most of the others have autosomal recessive disease with two mutations, one on each allele (in trans) affecting either the COL4A3 or COL4A4 gene.[5] Lenticonus and the central or peripheral retinopathy are found with both forms of inheritance.[6]

The distinction between X-linked and autosomal recessive inheritance is important because of the very different risks for other family members of being affected and, in particular, of developing end-stage renal failure. In X-linked Alport syndrome, the low de novo mutation rate (12\%)[7] means that most affected individuals inherit a mutation from a parent, and that other family members (siblings, grandparents, uncles, cousins) may also be affected. An affected male does not transmit the disease to any of his sons, but all his daughters inherit the mutation. An affected female transmits the mutation to half her sons and half her daughters. X-linked disease appears to skip a generation where a female carrying the mutation is undiagnosed.

In contrast, the parents and offspring of individuals with autosomal recessive Alport syndrome have hematuria but renal failure is uncommon, and when it occurs, often results from coincidental renal disease. Parents and offspring do not develop extraenal features because they have only a single copy of the disease-causing mutation. Most have the diagnosis of Thin basement membrane nephropathy.[8] The risk for the siblings of an individual with autosomal recessive Alport syndrome of inheriting both mutations and developing renal failure is $25 \%$.

The distinction between X-linked and autosomal recessive Alport syndrome has become easier with the widespread adoption of genetic testing. Mutation detection rates have also improved, especially with a combination of direct sequencing and techniques that identify large deletions, insertions or rearrangements.[9] However, each of the genes mutated in Alport syndrome is enormous and testing is expensive, 
so it is helpful to indicate the likely mode of inheritance when requesting genetic analysis.

There are often clues to the mode of inheritance from the family pedigree, clinical examination, and other investigations. X-linked Alport syndrome is more likely where disease occurs in multiple generations, males are affected more frequently and more severely than females, and, where the glomerular and epidermal membranes lack the collagen IV $\alpha 5$ chain.[10,11] Autosomal recessive inheritance is suspected where there is no family history of Alport syndrome or renal failure, a female develops renal failure,[12] both parents have hematuria, and the GBM lacks the collagen IV $\alpha 5$ chain but persists in the skin.[13] Autosomal recessive inheritance is also suspected where Alport syndrome occurs in the offspring of a consanguineous marriage.

However it is not always possible to deduce the mode of inheritance, for example, where there is no family history of Alport syndrome or renal failure because of de novo mutations, families are small, or affected individuals are young or do not have the typical phenotype.

This study reviewed a cohort of individuals from a single centre where the diagnosis of Alport syndrome and its mode of inheritance were confirmed with genetic testing, in order to determine how well clinical features differentiated recessive from $\mathrm{X}$-linked inheritance. 


\section{Results}

\section{Autosomal recessive Alport syndrome}

Fifteen patients ( 9 male, 6 female) were identified from 10 families with autosomal recessive Alport syndrome (Tables 1, 2). Three families (30\%) had multiple affected individuals (siblings in two, cousins in one) (Table 1). The affected cousins shared a common mutation but each also had another, different mutation. All affected relatives were in the same generation.

Two affected individuals were from consanguineous families and both had homozygous mutations. A further individual also had a homozygous mutation although her parents were not known to be related.

Eight of the families $(80 \%)$ had at least one nonsense mutation, and overall nonsense mutations accounted for 12 of the $20(60 \%)$ mutations.

Fourteen (93\%) patients had developed renal failure previously and the other had hematuria and proteinuria but normal renal function (Table 2). Eight (53\%) had developed end-stage renal failure before the age of 30 , and their overall average age at renal failure onset was $27.2 \pm 6.6$ years. Most had a hearing loss $(15,100 \%)$, lenticonus (12, $80 \%)$, and the central $(13,87 \%)$ and peripheral $(13,87 \%)$ retinopathies.

\section{X-linked Alport syndrome}

Forty patients (18 male, 22 female) were identified from 24 families with X-linked Alport syndrome (Tables 1, 2). Males and females were examined in 8 families. One female was from a large family with three examples of consanguinity including her parents, but she had a COL4A5 mutation and hence X-linked disease.

Overall, 19 (79\%) families had more than one affected member. Of the 14 families where the index case was male, there was another affected individual in 13 (93\%). Of the 17 families where the index case was female, there was another affected individual in 14 (82\%). Three males and 11 females (13/24 families, 54\%) had a relative with renal failure in another generation. 
Five families (36\%) had a pathogenic nonsense mutation, and overall nonsense mutations accounted for 5 of the $18(28 \%)$ mutations.

Fourteen males (78\%) with X-linked disease had developed renal failure, 12 (67\%) before the age of 30 , and their overall average age at onset of renal failure was 23.7 \pm 6.6 years. Seventeen had hearing loss (94\%), $10(56 \%)$ had lenticonus, $11(59 \%)$ had a central and $12(83 \%)$ had a peripheral retinopathy.

Females with X-linked disease developed end-stage renal failure uncommonly (one, $5 \%), 8(36 \%)$ had hearing loss, none had lenticonus, 4 (18\%) had a central retinopathy and $7(35 \%)$ had a peripheral retinopathy.

\section{Autosomal recessive disease and $X$-linked disease in males}

Patients with autosomal recessive disease were less likely to have an affected relative with renal failure than those with $X$-linked disease $(3 / 10$, and $13 / 14, p=0.002)$ (Table 1). They were also less likely to have an affected relative in another generation than those with $\mathrm{X}$-linked disease $(0 / 10$ and $13 / 24, \mathrm{p}=0.005)$.

Patients with autosomal recessive disease were more likely to have a nonsense mutation (or a mutation producing a downstream nonsense mutation) ( $80 \%$ and $36 \%, p=0.047$ ), and nonsense mutations accounted for more mutations than in $\mathrm{X}$ linked disease $(60 \%$ and $28 \%, p=0.06)$.

Males and females with autosomal recessive Alport syndrome were just as likely to have the typical clinical features as males with X-linked disease (Table 2). In particular, renal failure, lenticonus and the central retinopathy were very common in both X-linked and recessive inheritance.

\section{Autosomal recessive disease in females and X-linked disease in females}

Females with autosomal recessive disease were less likely to have an affected male relative than females with $X$-linked disease $(17 \%$ and $65 \%, p=0.07)$ (Table 2). They were also less likely to have a relative with renal failure in another generation (none, and $65 \%, p=0.01$ ). 
Females with autosomal recessive disease were more likely to develop renal failure ( $83 \%$ and $5 \%, p=0.0004$ ), and to develop renal failure before the age of 30 years $(67 \%$ and $5 \%, p=0.003)$ than females with $\mathrm{X}$-linked disease. They were also more likely to have a self-reported hearing loss $(100 \%$ and $36 \%, p=0.02)$ and lenticonus ( $67 \%$ and $0 \%, p<0.001)$. The central retinopathy occurred in $50 \%$ of females with recessive and $18 \%$ with $X$-linked disease $(p=0.14)$. There was no difference in the likelihood of a peripheral retinopathy ( $50 \%$ and $35 \%, p=0.63)$.

In this series, females with recessive disease were more likely to have a nonsense mutation, (or changes producing a downstream nonsense mutation) ( $83 \%$ and $29 \%$, $\mathrm{p}=0.05)$ and there was a trend for a relative increase in nonsense compared with other mutations (67\% and $29 \%, \mathrm{p}=0.07$ ) (Table 2). 


\section{Discussion}

Autosomal recessive Alport syndrome is less common than X-linked disease but the distinction between these forms of inheritance is important because of their different clinical implications, especially the risk of renal failure, for other family members.

This study indicated the increased risk of recessive inheritance where the disease affects only one generation, and where females have renal failure, hearing loss, lenticonus or central retinopathy.

This cohort represented about one third of our families with Alport syndrome and included all those individuals who had been fully clinically assessed and in whom the causative mutations were known. The major strengths of the study were that the patients were examined by the same clinicians at a single centre, had undergone retinal imaging, and both the disease and mode of inheritance were confirmed genetically.

Autosomal recessive Alport syndrome may be suspected from the family pedigree. In this study, all individuals with recessive inheritance were members of the same generation. In contrast, more than half the families with X-linked disease had a member with renal failure in another generation. However examination of the pedigree may also be misleading. Thus, one of our families with proven $\mathrm{X}$-linked disease included three consanguineous marriages, including the parents of an affected female with renal failure. Another individual with recessive disease was homozygous for an unusual mutation but was not from a known consanguineous family. Finally, one family included the two affected sons of maternal cousins, which suggested X-linked inheritance, but the sons shared a COL4A4 mutation with each also having a second different COL4A4 variant, consistent with recessive disease.

This study confirmed that recessive Alport syndrome presents in teenagers or adults more often than in children.[12] Overall, the risk of renal failure onset before the age of 30 years was the same for patients with autosomal recessive as for X-linked Alport syndrome. Only $5 \%$ of our females with X-linked disease developed renal failure, which is fewer than described elsewhere [14] and probably reflected our patients' younger age and our practice of screening extended family members. 
However renal failure onset before the age of 30 was more common in females with autosomal recessive Alport syndrome than in X-linked disease.

Hearing was assessed mainly by clinical questioning. All 5 females, aged 48 to 60 years, with X-linked Alport syndrome, who underwent formal audiometry had the typical high frequency hearing loss, suggesting hearing loss is common in older affected females.

Although all our participants underwent ophthalmological examination and retinal imaging, sometimes the retina could not be visualised adequately because of cataract. Both lenticonus and central retinopathy were very common in males and females with recessive Alport syndrome, but not in females with $X$-linked disease. The peripheral retinopathy is equally prevalent in both forms of inheritance and did not distinguish between them.

In this study, nonsense mutations were twice as common in individuals with recessive Alport syndrome, overall, and in females, compared with X-linked disease. In X-linked Alport syndrome, nonsense mutations are associated with a more severe phenotype, with early onset renal failure and extrarenal manifestations.[7, 14, 15] It is not clear whether nonsense mutations were increased in our patient cohort because they had more extrarenal Alport features. Only one of our patients with recessive disease had no nonsense mutation and her disease was mild. By the age of 32 , she had hematuria and proteinuria but not renal impairment, or ocular abnormalities. There are few data on genotype-phenotype correlations in autosomal recessive disease, and our patients with their mainly nonsense mutations may have had a correspondingly worse phenotype than is generally found.

In conclusion, clinical features in individuals with autosomal recessive Alport syndrome resemble those in males with X-linked disease, and females with autosomal recessive inheritance are more likely to have early onset renal failure, hearing loss, lenticonus and, possibly, the central retinopathy than those with $\mathrm{X}$ linked disease. Further studies will indicate whether nonsense mutations are associated with a worse phenotype than missense mutations in recessively-inherited disease. 


\section{Concise methods}

Patients were recruited from those attending the Inherited renal disease clinics at Austin Health or Northern Health between 1995 and 2012. They were suspected to have Alport syndrome on the basis of GBM lamellation in a renal biopsy in themselves or another affected family member.[16]

The diagnosis of Alport syndrome and mode of inheritance were confirmed on genetic testing. Mutations were demonstrated by genomic or cDNA sequencing in the laboratories at Northern Health or at Guy's and St Thomas' Hospital Trust using methods described previously.[17] Autosomal recessive disease was diagnosed when patients had two pathogenic mutations in the COL4A3 or COL4A4 gene, and $X$-linked disease when they had a single pathogenic COL4A5 mutation.

All individuals were examined clinically by the same renal physician (JS) and ophthalmologist (DC). Hearing loss was self-reported but in some cases audiometry was performed. All individuals were studied for ocular abnormalities without the ophthalmologist being aware of the patients' disease status. Patients were examined for the oil droplet sign of anterior lenticonus using a hand-held retinoscope, and their pupils dilated with $1 \%$ tropicamide (Minims) and their optic fundi examined for the central and peripheral retinopathies by direct ophthalmoscopy, slit lamp biomicroscopy with a 78D lens, and by indirect ophthalmoscopy with a 20D lens. The peripheral retina was defined at least 2 optic disc diameters from the foveola. All patients also underwent retinal photography of both optic fundi with at least one view centred on the foveola and another on the optic disc (KOWA non-mydriatic camera, Japan).

This study had the approval of the Human Research Ethics Committee of Austin Health and Northern Health, and all patients provided signed informed consent.

\section{Statistical analysis}

Categorical data were compared using Fisher's exact test and continuous data with the t test (Graph pad software Inc). 


\section{Acknowledgements}

We would like to thank the many patients and their families who took part in these studies. This work was funded in part by the Alport Foundation of Australia.

This work was presented as a Poster at the American Society of Nephrology meeting in San Diego, in October 2012. The mutations in these patients have been described in a separate publication.

\section{Statement of Competing Financial Interests}

The authors have no Competing Financial Interests to declare. 
Table 1: Genetic features in autosomal recessive Alport syndrome and males with X-linked Alport syndrome; and in females with autosomal recessive or $X$-linked disease

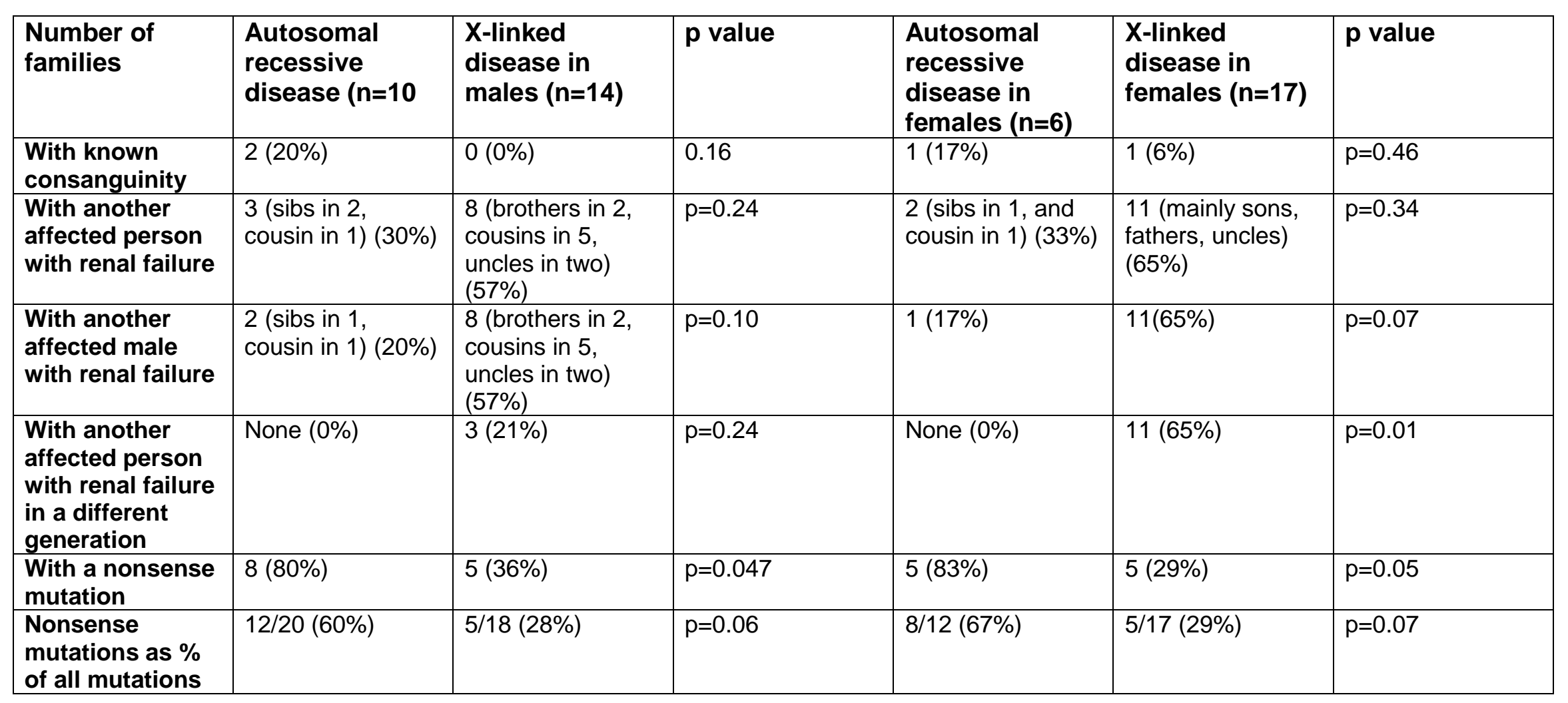


Table 2: Clinical features in autosomal recessive Alport syndrome and males with X-linked Alport syndrome; and in females with autosomal recessive or X-linked disease

\begin{tabular}{|c|c|c|c|c|c|c|}
\hline & $\begin{array}{l}\text { Autosomal } \\
\text { recessive } \\
\text { disease }(n=15)\end{array}$ & $\begin{array}{l}\text { X-linked } \\
\text { disease in } \\
\text { males }(n=18)\end{array}$ & p value & $\begin{array}{l}\text { Autosomal } \\
\text { recessive } \\
\text { disease in } \\
\text { females }(n=6)\end{array}$ & $\begin{array}{l}\text { X-linked disease } \\
\text { in females } \\
(n=22)\end{array}$ & p value \\
\hline Gender (M, F) & $9 \mathrm{M}, 6 \mathrm{~F}$ & $18 \mathrm{M}$ & & $6 \mathrm{~F}$ & $22 F$ & \\
\hline $\begin{array}{l}\text { Age (mean, SD, } \\
\text { years) }\end{array}$ & $37.3 \pm 9.6$ & $35.3 \pm 10.8$ & $\begin{array}{l}\text { Mean difference } \\
2.0(-5.33 \text { to } 9.32) \\
p=0.58\end{array}$ & $40.1 \pm 8.9$ & $43.2 \pm 14.6$ & $\begin{array}{l}\text { Mean difference } \\
-3.10(-16.40 \text { to } \\
10.20), p=0.63\end{array}$ \\
\hline Renal failure & $14(93 \%)$ & $14(78 \%)$ & $\mathrm{p}=0.35$ & $5(83 \%)$ & $1(5 \%)$ & $\mathrm{p}=0.0004$ \\
\hline $\begin{array}{l}\text { Renal failure }<30 \\
\text { years }\end{array}$ & $8(53 \%)$ & $12(67 \%)$ & $p=0.49$ & $4(67 \%)$ & $1(5 \%)$ & $p=0.003$ \\
\hline $\begin{array}{l}\text { Age at onset of } \\
\text { renal failure } \\
\text { (mean, SD, years) }\end{array}$ & $27.2 \pm 6.6$ & $23.7 \pm 9.7$ & $\begin{array}{l}\text { Mean difference } \\
3.5(-2.95 \text { to } 9.95) \\
p=0.27\end{array}$ & $25.0 \pm 7.1$ & 25 & \\
\hline Hearing loss & $15(100 \%)$ & $17(94 \%)$ & $p=1.00$ & $6(100 \%)$ & $8(36 \%)$ & $p=0.02$ \\
\hline Lenticonus & $12(80 \%)$ & $10(56 \%)$ & $p=0.68$ & $4(67 \%)$ & $0(0 \%)$ & $p<0.001$ \\
\hline $\begin{array}{l}\text { Central } \\
\text { retinopathy }\end{array}$ & $13(87 \%)$ & $11 / 17(59 \%)$ & $p=0.23$ & $3(50 \%)$ & $4(18 \%)$ & $p=0.14$ \\
\hline $\begin{array}{l}\text { Peripheral } \\
\text { retinopathy }\end{array}$ & $13(87 \%)$ & $12 / 17(83 \%)$ & $p=0.40$ & $3(50 \%)$ & $7 / 20(35 \%)$ & $p=0.64$ \\
\hline
\end{tabular}




\section{References}

1. Gubler M, Levy M, Broyer M, Naizot C, Gonzales G, Perrin D, Habib R (1981) Alport's syndrome. A report of 58 cases and a review of the literature. Am J Med 70:493-505.

2. Flinter FA, Cameron JS, Chantler C, Houston I, Bobrow M (1988) Genetics of classic Alport's syndrome. Lancet 2:1005-1007.

3. Feingold J, Bois E, Chompret A, Broyer M, Gubler MC, Grunfeld JP (1985) Genetic heterogeneity of Alport syndrome. Kidney Int 27:672-677.

4. Barker DF, Hostikka SL, Zhou J, Chow LT, Oliphant AR, Gerken SC, Gregory MC, Skolnick MH, Atkin CL, Tryggvason K (1990) Identification of mutations in the COL4A5 collagen gene in Alport syndrome. Science 248:1224-1227.

5. Mochizuki T, Lemmink HH, Mariyama M, Antignac C, Gubler MC, Pirson Y, Verellen-Dumoulin C, Chan B, Schroder CH, Smeets HJ, Reeders ST (1994) Identification of mutations in the alpha 3(IV) and alpha 4(IV) collagen genes in autosomal recessive Alport syndrome. Nat Genet 8:77-81.

6. Colville D, Savige J, Morfis M, Ellis J, Kerr P, Agar J, Fasset R (1997) Ocular manifestations of autosomal recessive Alport syndrome. Ophthalmic Genet 18:119-128.

7. Jais JP, Knebelmann B, Giatras I, De Marchi M, Rizzoni G, Renieri A, Weber M, Gross O, Netzer KO, Flinter F, Pirson Y, Verellen C, Wieslander J, Persson U, Tryggvason K, Martin P, Hertz JM, Schroder C, Sanak M, Krejcova S, Carvalho MF, Saus J, Antignac C, Smeets H, Gubler MC (2000) $X$-linked Alport syndrome: natural history in 195 families and genotypephenotype correlations in males. J Am Soc Nephrol 11:649-657.

8. Savige J, Rana K, Tonna S, Buzza M, Dagher H, Wang YY (2003) Thin basement membrane nephropathy. Kidney Int 64:1169-1178.

9. Hertz JM, Thomassen M, Storey H, Flinter F (2012) Clinical utility gene card for: Alport syndrome. Eur J Hum Genet 20.

10. Nakanishi K, Yoshikawa N, lijima K, Kitagawa K, Nakamura H, Ito H, Yoshioka K, Kagawa M, Sado Y (1994) Immunohistochemical study of alpha 1-5 chains of type IV collagen in hereditary nephritis. Kidney Int 46:14131421.

11. van der Loop FT, Monnens LA, Schroder $\mathrm{CH}$, Lemmink $\mathrm{HH}$, Breuning $\mathrm{MH}$, Timmer ED, Smeets HJ (1999) Identification of COL4A5 defects in Alport's syndrome by immunohistochemistry of skin. Kidney Int 55:1217-1224.

12. Torra R, Badenas C, Cofan F, Callis L, Perez-Oller L, Darnell A (1999) Autosomal recessive Alport syndrome: linkage analysis and clinical features in two families. Nephrol Dial Transplant 14:627-630.

13. Gubler MC, Knebelmann B, Beziau A, Broyer M, Pirson Y, Haddoum F, Kleppel MM, Antignac C (1995) Autosomal recessive Alport syndrome: immunohistochemical study of type IV collagen chain distribution. Kidney Int 47:1142-1147.

14. Jais JP, Knebelmann B, Giatras I, De Marchi M, Rizzoni G, Renieri A, Weber M, Gross O, Netzer KO, Flinter F, Pirson Y, Dahan K, Wieslander J, Persson U, Tryggvason K, Martin P, Hertz JM, Schroder C, Sanak M, Carvalho MF, Saus J, Antignac C, Smeets H, Gubler MC (2003) X-linked Alport syndrome: natural history and genotype-phenotype correlations in girls and women belonging to 195 families: a "European Community Alport Syndrome Concerted Action" study. J Am Soc Nephrol 14:2603-2610. 
15. Tan R, Colville D, Wang YY, Rigby L, Savige J (2010) Alport retinopathy results from "severe" COL4A5 mutations and predicts early renal failure. Clin J Am Soc Nephrol 5:34-38.

16. Rumpelt HJ, Langer KH, Scharer K, Straub E, Thoenes W (1974) Split and extremely thin glomerular basement membranes in hereditary nephropathy (Alport's syndrome). Virchows Arch A Pathol Anat Histol 364:225-233.

17. Hanson $H$, Storey $H$, Pagan J, Flinter $F(2011)$ The value of clinical criteria in identifying patients with X-linked Alport syndrome. Clin J Am Soc Nephrol 6:198-203. 